\title{
A Novel Microstrip Antenna with Double Notches
}

\author{
Xu Liqin ${ }^{1}$, Zhong Jin ${ }^{1}$ and Wang Chonghua ${ }^{2}$ \\ ${ }^{1}$ College of Electronic Science \& Engineering, Nanjing University of Posts and Telecommunications, China \\ ${ }^{2}$ China Mobile Communications Group Co., Ltd. Shandong Rizhao Branch, China \\ taihong07@163.com,xulq@njupt.edu.cn
}

\begin{abstract}
This paper study on the the novel octagonal UWB microstrip antenna and do double notches and optimization on it. The antenna covers the bandwidth from $3.1 \mathrm{GHz} \sim 10.6 \mathrm{GHz}$ completely and has two band-notches in the frequency ranges of $3.4 \mathrm{GHz}$ to 4.5 $\mathrm{GHz}$ and $5.15 \mathrm{GHz}$ to $5.75 \mathrm{GHz}$ respectively avoiding the interferences of WIMAX $(3.3 \mathrm{GHZ} \sim 3.6 \mathrm{GHz})$, C-band radar communication signal $(3.7 \mathrm{GHz} \sim 4.2 \mathrm{GHz})$ and WLAN $(5.15 \mathrm{GHz}$ $\sim 5.825 \mathrm{GHz}$ ). Software simulation results show that the antenna performance is good, and in addition, its features of simple structure and small size are suitable for modern wireless communication systems.
\end{abstract}

Index Terms - performance, Ultra-wideband (UWB), double notches, microstrip-transmission, VSWR

\section{Introduction}

The UWB antenna raises much concern due to its wide bandwidth. But in the FCC regulations for UWB spectrum $(3.1 \sim 10.6 \mathrm{GHz})$, there are many widely used narrow-band communication systems, such as the Worldwide Interoperability for Microwave Access (WIMAX: 3.3 3.6 $\mathrm{GHz}$ ), Wireless Local Area Networks (WLAN: 5.15 5.825 $\mathrm{GHz}$ ) and C-band radar communication systems (3.7 4.2 $\mathrm{GHz}$ ). Isolation is needed to reduce the interferences between these narrow-band systems and UWB systems. The traditional approaches not only increase the complexity of the system, and the cost is also higher. In contrast, using notched antenna has lower cost and is easier to implement filtering, therefore the UWB antenna with notch function has a very important research value.

According to the design requirements for UWB antennas, this paper selects a new octagonal UWB printed antenna designed by $\mathrm{Hu}$ Wei, etc, as in [1]. The four identical rightangled triangles are cut from the four corners of rectangular radiating patch printed on the substrate. The VSWR of the final antenna is less than 2 in the frequency ranges of $2.9 \mathrm{GHz}$ to $11 \mathrm{GHz}$ covering the frequency band which the UWB antennas require. Then a pair of UWB with double notches is gotten by etching two T-shaped slots on the octagonal patch.

\section{The Structure and Properties of the Antenna}

Fig. 1 shows the geometry and configuration of the UWB antenna. The antenna was fabricated on an $\mathrm{h}=1.0 \mathrm{~mm}$ FR4 epoxy substrate with the dielectric constant $\epsilon_{\mathrm{r}}=4.4$ and loss tangent $\tan \delta=0.02$. As shown in the figure, the ground is a rectangle which is etched in the middle and at both ends. Two
T-shaped slots are etched on the radiator which is a polygonal patch improved from a rectangular patch to get double notch. The polygonal radiator is fed by a $50-\Omega$ microstrip transmission line, which is etched with two little rectangular slots to improve the performance of the antenna. The electromagnetic software HFSS is employed to perform the design and optimization process. The design parameters are $\mathrm{W}=31.5 \mathrm{~mm}, \mathrm{~L}=38 \mathrm{~mm}, \mathrm{a}=5 \mathrm{~mm}, \mathrm{~b}=1.2 \mathrm{~mm}, \mathrm{~L} 1=1.9 \mathrm{~mm}$, $\mathrm{W} 1=9 \mathrm{~mm}, \mathrm{~L} 2=2.5 \mathrm{~mm}, \mathrm{~W} 2=5.2 \mathrm{~mm}, \mathrm{Lt}=19 \mathrm{~mm}, \mathrm{Lg}=21.2$ $\mathrm{mm}, \mathrm{Ln} 1=5 \mathrm{~mm}, \mathrm{Wn} 1=8.3 \mathrm{~mm}, \mathrm{~W} 01=0.3 \mathrm{~mm}, \mathrm{Ln} 2=5 \mathrm{~mm}$, $\mathrm{Wn} 2=4.8 \mathrm{~mm}$ and $\mathrm{W} 02=0.5 \mathrm{~mm}$. The design size of the radiating patch is $15.6 \mathrm{~mm} \times 18.3 \mathrm{~mm}$.

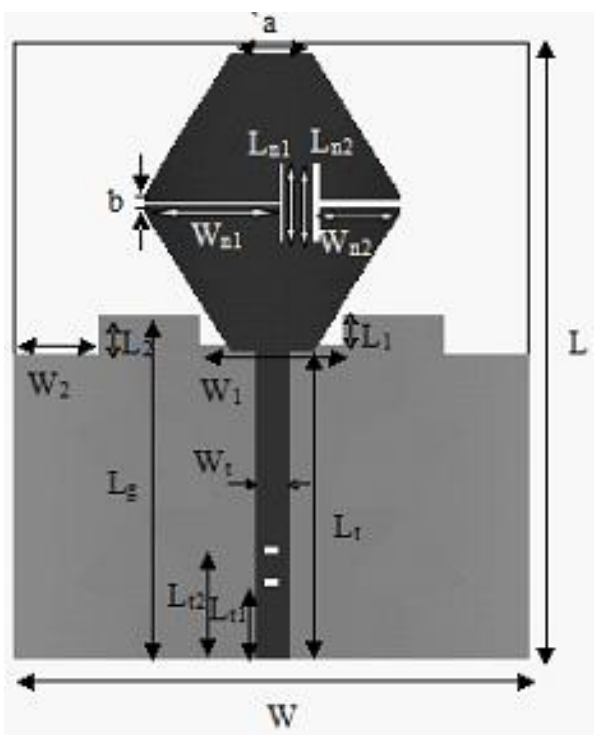

Fig. 1 Geometry and configuration of the UWB antenna.

Fig.2(a) and Fig.2(b) show the return loss (-S11) vs. frequency and VSWR vs. frequency of the UWB antenna respectively. The frequency band for this antenna extends from $3.1 \mathrm{GHz} 16 \mathrm{GHz}$, which is covering the band from 3.1 $\mathrm{GHz} 10.6 \mathrm{GHz}$ completely. Two notches (in the $3.4 \mathrm{GHz}$ to $4.5 \mathrm{GHz}$ range and in the $5.15 \mathrm{GHz}$ to $5.75 \mathrm{GHz}$ ) make the antenna avoid the interference of WIMAX (3.3 GHz 3.6 GHZ), C-band radar communication $(3.7 \mathrm{GHz} 4.2 \mathrm{GHz}$ ) and WLAN (5.15 GHz 5.825 GHz). 


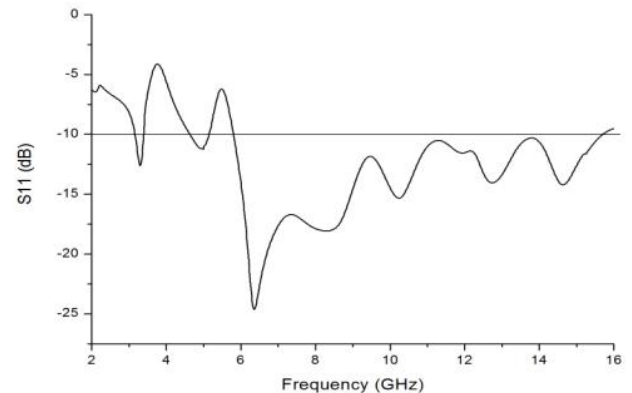

Fig. 2(a) S11 vs. frequency of UWB antenna.

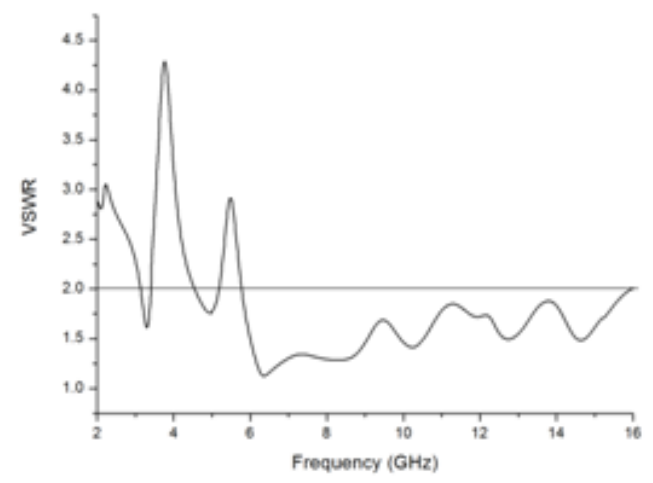

Fig. 2(b) VSWR vs. frequency of UWB antenna.

\section{The Novel UWB Antenna Design and Analysis}

The UWB antenna gets double notches due to the two Tshaped slots on the radiating patch. The left $\mathrm{T}$-shaped slot produces the notch in the $3.4 \mathrm{GHz}$ to $4.5 \mathrm{GHz}$ range and the right one produces the notch in the $5.15 \mathrm{GHz}$ to $5.75 \mathrm{GHz}$ range. The length and width of the slots will affect the performance of the double notches. Fig.3(a) and Fig.3(b) show that the length and the width of the right T-shaped slot changing will affect the left slot, thus influencing the bandwidth and center frequency of the double notches.

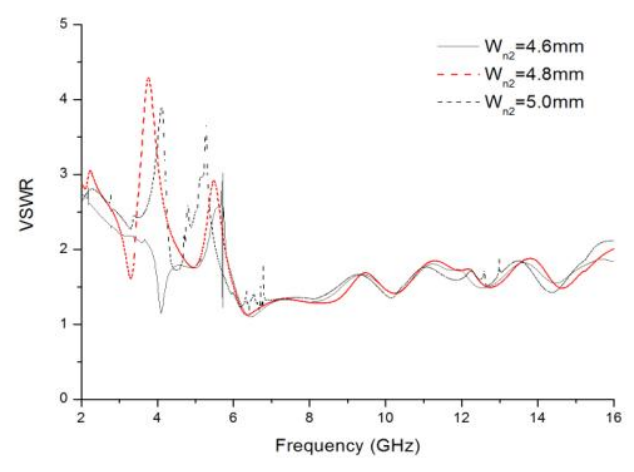

Fig. 3(a) The change in the antenna performance when Wn2 changes.

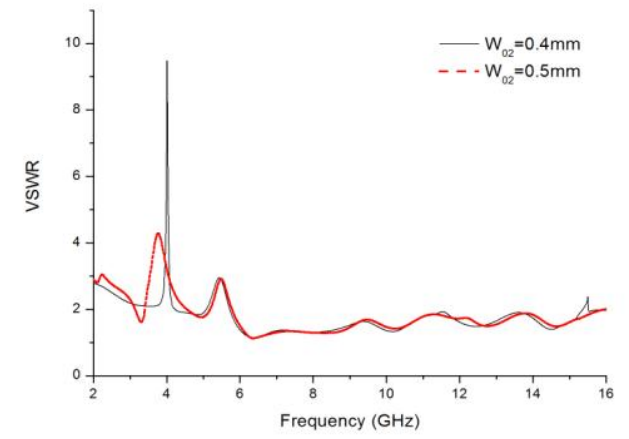

Fig. 3(b) The change in the antenna performance when W02 changes.

For better notch performance, two little slots are etched on the microstrip transmission line of the antenna. The distances from two slots to the bottom edge of the substrate are $\mathrm{Lt} 1=4.5 \mathrm{~mm}$ and $\mathrm{Lt} 2=6.5 \mathrm{~mm}$ respectively. The sizes of the two slots are both $1 \mathrm{~mm} \times 0.5 \mathrm{~mm}$. Fig. 4 shows that the two slots have a great influence on the performance of the antenna and these are vital designs of the UWB antenna.

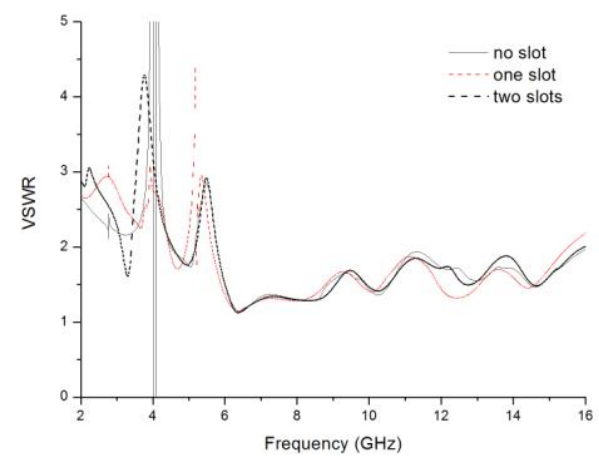

Fig. 4 The influence of the slots etched on the microstrip transmission line on the UWB antenna.

Fig.5(a) and Fig.5(b) show the E-plane and H-plane radiation pattern of the UWB antenna at 3, 6 and $9 \mathrm{GHz}$ respectively. The E-plane and $\mathrm{H}$-plane radiation pattern is better omni-directional at lower frequencies.

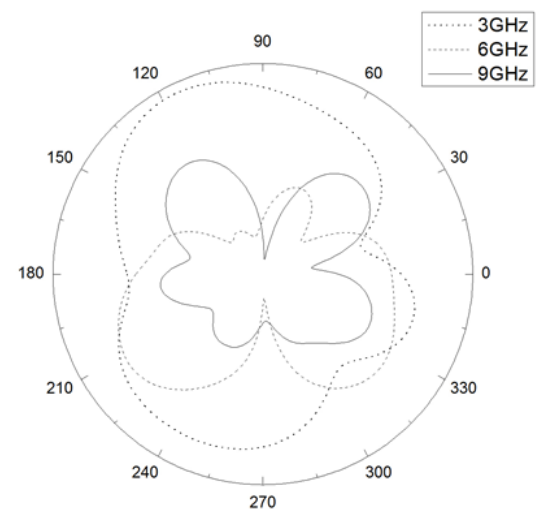

Fig. 5(a) Simulated E-plane radiation pattern of the UWB antenna at 3, 6 and $9 \mathrm{GHz}$. 


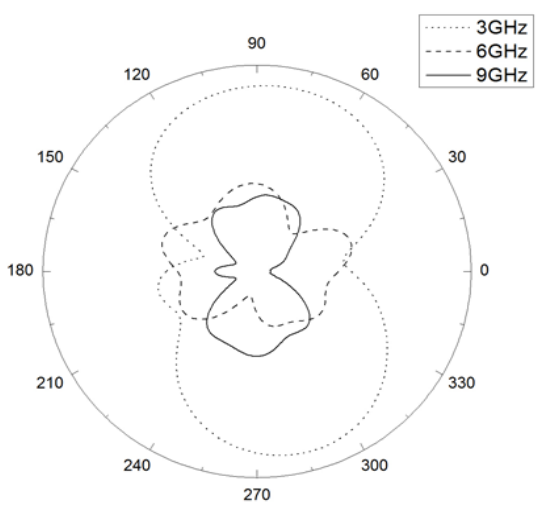

Fig. 5(b) Simulated H-plane radiation pattern of the UWB antenna at 3,6 and $9 \mathrm{GHz}$.

\section{Conclusions}

A UWB antenna configuration with double notches is presented in this paper. Two T-shaped slots etched on the radiator and two little rectangular slots etched on the microstrip transmission line play a vital role in realizing the performance of the UWB antenna. The proposed UWB antenna configuration is simple and compact in size with stopbands in the ranges of WIMAX, WLAN and C-band.

\section{References}

[1] Hu Wei, Zhang Jian Hua and Ma Liang, "A notched UWB antenna with a T-shapede slot," Journal of HeFei University of Technology (natural science edition), vol. 34, no. 7, 2011.

[2] Zhang Ming and Geng Youlin, "The design of UWB antenna with double notches," High Power Laser and Particle Beams, vol. 24. no. 1, 2012.

[3] Thomas K G and Sreenivasan M, "A simple ultrawideband planar rectangular printed antenna with band dispensation," IEEE Trans on Antenna and Propagation, vol. 58, no. 1, pp. 27-34, 2010.

[4] Hong Chongyu, Ling C W and Tarn I Y, "Design of a planar ultrawideband antenna with a new band-notch structure," IEEE Trans on Antenna and Propagation, vol. 55, no. 12, pp. 3391-3397, 2007.

[5] Liang Jianxin, Choo C Chiau and Chen Xiaodong, "Study of a printed circular disc monopole antenna for UWB systems," IEEE Trans on Antennas Propa, vol. 53, no. 11, pp. 3500-3504, 2005. 